\title{
Choice of inbred rat strain impacts lethality and disease course after respiratory infection with Rift Valley Fever Virus
}

\author{
Jacquelyn M. Bales ${ }^{1}$, Diana S. Powell ${ }^{1}$, Laura M. Bethel ${ }^{1}$, Douglas S. Reed ${ }^{1,2}$ and Amy L. Hartman ${ }^{1,3 *}$ \\ ${ }_{1}^{1}$ Regional Biocontainment Laboratory, Center for Vaccine Research, University of Pittsburgh, Pittsburgh, PA, USA \\ 2 Department of Immunology, University of Pittsburgh School of Medicine, Pittsburgh, PA, USA \\ ${ }^{3}$ Department of Infectious Disease and Microbiology, University of Pittsburgh Graduate School of Public Health, Pittsburgh, PA, USA
}

Edited by:

Chad J. Roy, Tulane University, USA

Reviewed by:

Jose A. Bengoechea, Fundacion

Caubet-CIMERA Illes Balears, Spain

Chad J. Roy, Tulane University, USA

*Correspondence:

Amy L. Hartman, Regional

Biocontainment Laboratory, Center

for Vaccine Research, University of

Pittsburgh, 3501 Fifth Ave.,

Pittsburgh, PA 15213, USA

e-mail: hartman2@pitt.edu
Humans infected with Rift Valley Fever Virus (RVFV) generally recover after a febrile illness; however, a proportion of patients progress to a more severe clinical outcome such as hemorrhagic fever or meningoencephalitis. RVFV is naturally transmitted to livestock and humans by mosquito bites, but it is also infectious through inhalational exposure, making it a potential bioterror weapon. To better understand the disease caused by inhalation of RVFV, Wistar-Furth, ACl, or Lewis rats were exposed to experimental aerosols containing virulent RVFV. Wistar-Furth rats developed a rapidly progressing lethal hepatic disease after inhalational exposure; $\mathrm{ACl}$ rats were 100-fold less susceptible and developed fatal encephalitis after infection. Lewis rats, which do not succumb to parenteral inoculation with RVFV, developed fatal encephalitis after aerosol infection. RVFV was found in the liver, lung, spleen, heart, kidney and brain of Wistar Furth rats that succumbed after aerosol exposure. In contrast, RVFV was found only in the brains of $\mathrm{ACl}$ or Lewis rats that succumbed after aerosol exposure. Lewis rats that survived s.c. infection were not protected against subsequent re-challenge by aerosol exposure to the homologous virus. This is the first side-by-side comparison of the lethality and pathogenesis of RVFV in three rat strains after aerosol exposure and the first step toward developing a rodent model suitable for use under the FDA Animal Rule to test potential vaccines and therapeutics for aerosol exposure to RVFV.

Keywords: Rift Valley Fever Virus, aerosol exposure, respiratory infection, $\mathrm{LD}_{50}$, inbred rat strain

\section{INTRODUCTION}

Rift Valley Fever Virus (RVFV), a mosquito-borne member of the Bunyaviridae family of segmented negative sense RNA viruses, causes large explosive epidemics of severe disease in livestock that have significant economic impact in Africa and the Arabian Peninsula. Epizootics of RVFV are characterized by high mortality in young animals, as well as abortion rates in pregnant animals that approach 100\% (Easterday et al., 1962; Coetzer and Barnard, 1977; Coetzer and Theodoridis, 1982). As a consequence of a large number of infected livestock, the disease overflows into the surrounding human population, often infecting $>100,000$ people during a given outbreak (Laughlin et al., 1979; Meegan et al., 1979; Jouan et al., 1989). While RVFV is transmissible to humans by mosquito bite, the virus also spreads rapidly by mucosal and aerosol infection caused by humans handling infected animal carcasses (Hoogstraal et al., 1979; Madani et al., 2003; Mohamed et al., 2010).

Human infections with RVFV begin with a short incubation period followed by a significant fever, headache, myalgia, anorexia, and, in some cases, nausea and vomiting (Easterday, 1965; Laughlin et al., 1979). In the majority of uncomplicated RVFV infections, a full recovery occurs within 2 weeks (Laughlin et al., 1979). However, a small proportion of patients (1-2\%) progress to a more severe clinical outcome which primarily include either hemorrhagic fever with jaundice or meningoencephalitis (Abdel-Wahab et al., 1978; Laughlin et al., 1979; McIntosh et al., 1980; Madani et al., 2003). Retinitis and other ocular manifestations can also occur. Given the large number of humans infected during the known outbreaks, a significant number of individuals can be hospitalized. The case fatality rate for hospitalized patients is between 10 and 20\% (Laughlin et al., 1979; McIntosh et al., 1980; Madani et al., 2003). The mechanisms underlying the different human clinical outcomes are not well-understood; however, a greater understanding of the pathophysiologic mechanisms behind the divergent human clinical outcomes is necessary to design effective medical countermeasures (MCMs) to combat RVFV. While it is thought that the primary route of transmission of RVFV in natural outbreaks is by mosquito vectors, RVFV can be infectious and virulent when inhaled by humans (Francis and Magill, 1935; Smithburn et al., 1949; Hoogstraal et al., 1979) or experimental animals (Miller et al., 1963; Anderson et al., 1991a; Morrill and Peters, 2011).

Studies performed in the 1980s (Peters and Slone, 1982; Anderson et al., 1987; Anderson and Peters, 1988) suggest that infection of different inbred rat strains with the virulent ZH501 strain of RVFV results in three distinct disease patterns that may serve as models for the disparate human clinical outcome of RVFV infection. In these reports, Wistar-Furth (WF) rats develop 
a severe hepatic disease when inoculated subcutaneously (s.c.) with RVFV, while August-Copenhagen-Irish (ACI) rats develop encephalitis (Bucci et al., 1981; Peters and Anderson, 1981; Peters and Slone, 1982; Anderson et al., 1987; Bird et al., 2007). In contrast, s.c.-injected RVFV causes little or no mortality in the Lewis rat strain, although the Lewis rats were viremic and developed RVFV-specific antibody responses (Peters and Slone, 1982; Anderson et al., 1987). Anderson and colleagues showed that Wistar-Furth rats were at least partially protected against aerosol challenge with virulent virus by a formalin-inactivated RVFV vaccine administered subcutaneously (Anderson et al., 1991a). Vaccinated Wistar-Furth rats that succumbed to the disease did not develop hepatic disease but instead developed delayed-onset encephalitis. Little data exists on the effect of aerosol exposure to RVFV in other strains of rat.

The overall goal of the studies reported here is to determine whether inhalation of RVFV alters the virulence and disease course of RVFV in Wistar-Furth, ACI, or Lewis rat strains relative to what had been reported previously for subcutaneous inoculation (Bucci et al., 1981; Peters and Slone, 1982; Anderson et al., 1987). For Wistar-Furth and ACI rats, aerosol infection with RVFV resembled subcutaneous inoculation in terms of disease course and outcome, although RVFV was more lethal in ACI rats by the aerosol route than what had previously been reported for s.c. inoculation. Lewis rats developed fatal encephalitis after aerosol infection with RVFV, which is different from what has been reported for s.c. inoculation where only mild disease and viremia were noted. This report is the first step toward developing a rodent model suitable for use under the FDA Animal Rule (Food and Drug Administration, 2002) to test potential vaccines and therapeutics for aerosol exposure to RVFV.

\section{MATERIALS AND METHODS}

\section{BIOSAFETY AND REGULATORY INFORMATION}

All work with live RVFV was conducted at biosafety level (BSL)-3 in the University of Pittsburgh Regional Biocontainment Laboratory (RBL). For respiratory protection, all personnel wore powered air purifying respirators (PAPRs; $3 \mathrm{M} \mathrm{GVP-1} \mathrm{PAPR} \mathrm{with}$ L-series bumpcap) or used a class III biological safety cabinet. All animals were housed in individually ventilated micro-isolator caging (Allentown, Inc., Allentown, NJ). Vesphene II se (1:128 dilution, Steris Corporation, Erie, PA) was used to disinfect all liquid wastes and surfaces associated with the agent. All solid wastes, used caging, and animal wastes, were steam-sterilized. Animal carcasses were digested via alkaline hydrolysis (Peerless Waste Solutions, Holland, MI). The University of Pittsburgh Regional Biocontainment Laboratory is a Registered Entity with the CDC/USDA for work with Rift Valley Fever. All animal work described here was reviewed and approved by the University of Pittsburgh IACUC (protocol \#1005740).

\section{VIRUS PROPAGATION AND CULTURE}

RVFV strain ZH501 was kindly provided by Barry Miller (CDC, Ft. Collins, CO) and Stuart Nichol (CDC, Atlanta). Prior to receipt, the virus was generated from reverse genetics plasmids (Bird et al., 2007) containing the wild-type ZH501 sequence, which was confirmed by sequencing. Virus was propagated on VeroE6 cells using standard methods. For virus quantitation, standard plaque assays were performed using an agarose overlay $(1 \times$ minimum essential medium, $2 \%$ FBS, $1 \%$ penicillin/streptomycin, HEPES buffer, and $0.8 \%$ SeaKem agarose), incubated for 3 days at $37^{\circ} \mathrm{C}$, and visualized using crystal violet. For titration of tissue samples, tissue pieces were homogenized in $2 \times$ volume of DMEM $+10 \%$ FBS using an Omni tissue homogenizer (Omni International), followed by a standard plaque assay on the homogenate.

\section{ANIMAL STUDIES}

Female Wistar-Furth (WF/NHsd), August Copenhagan Irish (ACI/SegHsd), and Lewis (LEW/SsNHsd) rats (8-10 weeks old) were obtained from Harlan Laboratories. All rats were provided rodent food (IsoPro Rodent 3000) and water ad libitum. All rats had implantable, programmable temperature transponders (IPTT-300; Bio Medic Data Systems, Seaford, DE) inserted subcutaneously between the shoulder blades for identification and temperature monitoring. Probit analysis was conducted using NCSS 97 statistical software (NCSS, Kaysville, Utah).

\section{AEROSOL EXPOSURE OF ANIMALS}

Prior to animal studies, a number of "sham" aerosol exposures were conducted to determine the aerosol characteristics of RVFV. The RVFV stock was diluted to the desired nebulizer concentration in DMEM containing 2\% FBS, antifoam, and glycerol, and subsequently kept on ice until used. Rats were exposed for $10 \mathrm{~min}$ in a whole-body aerosol chamber to a small-particle aerosol created by a 3 -jet Collison nebulizer (BGI, Inc., Waltham, MA) controlled by the AeroMP aerosol exposure control system (Biaera Technologies, Hagerstown, MD). A humidification chamber (Biaera Technologies) was used to increase humidification in

Table 1 | Average time to death of inbred rat strains infected with RVFV by aerosol exposure.

\begin{tabular}{|c|c|c|c|}
\hline $\begin{array}{l}\text { Average presented } \\
\text { dose (pfu) }\end{array}$ & \# dead/total & $\begin{array}{l}\text { Average time to } \\
\text { death (days) }\end{array}$ & $L_{50}$ (pfu) \\
\hline Wistar-Furth: & - & - & 2 \\
\hline 0.4 & $1 / 6$ & 8 & \\
\hline 5 & $5 / 6$ & 6.3 & \\
\hline 40 & $6 / 6$ & 5.5 & \\
\hline 240 & $6 / 6$ & 3.5 & \\
\hline ACl: & & & 123 \\
\hline 0.4 & $0 / 6$ & N/A & \\
\hline 2 & $1 / 6$ & 14 & \\
\hline 20 & $2 / 8$ & 13 & \\
\hline 250 & $4 / 8$ & 8 & \\
\hline 3900 & $6 / 6$ & 6 & \\
\hline Lewis: & & & 112 \\
\hline 1.5 & $0 / 6$ & N/A & \\
\hline 30 & $0 / 6$ & N/A & \\
\hline 350 & $5 / 6$ & 7.5 & \\
\hline 4400 & $8 / 8$ & 6.8 & \\
\hline
\end{tabular}




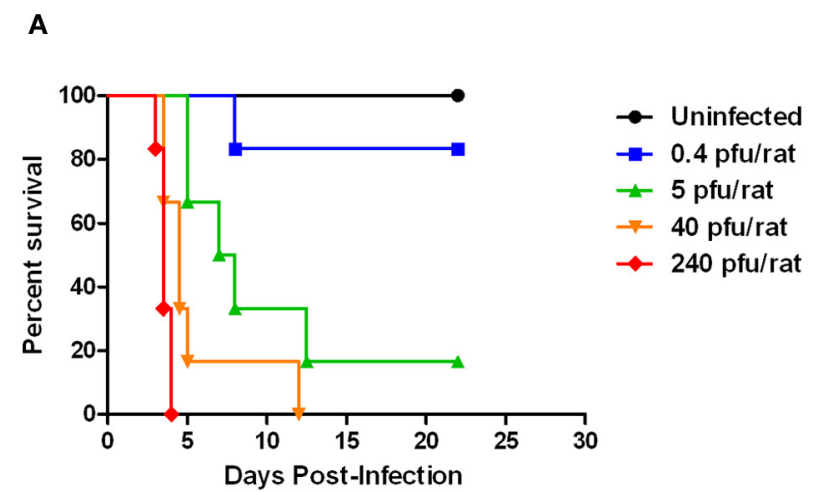

C

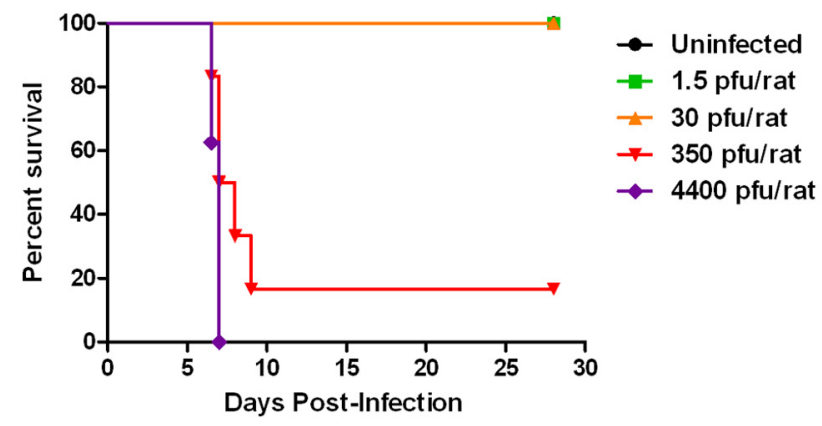

B

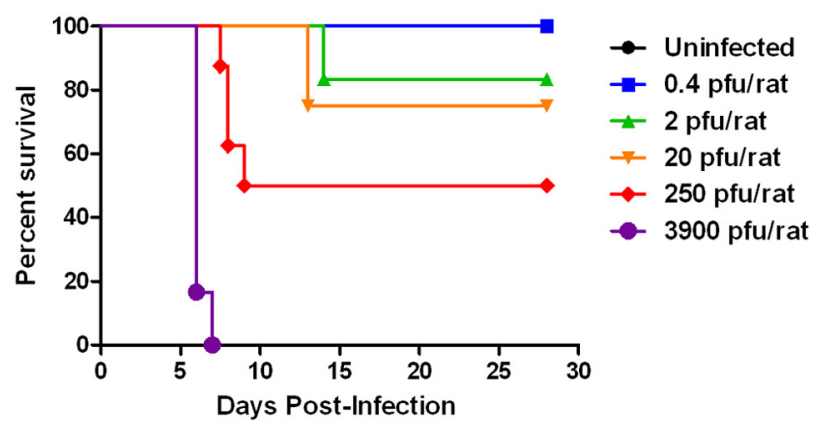

D

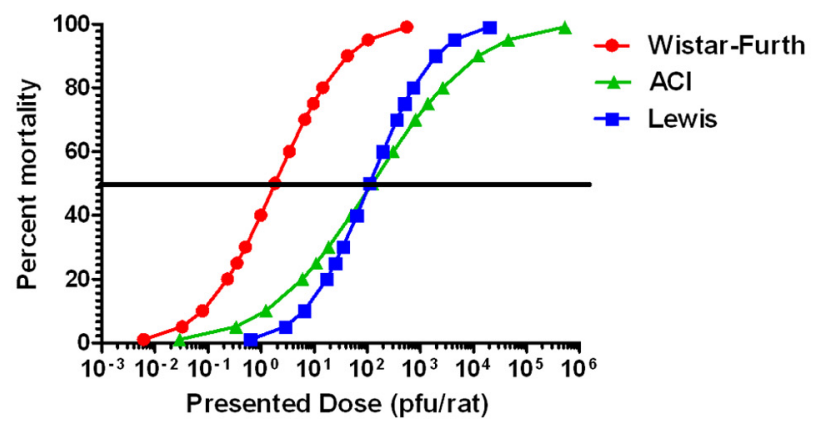

FIGURE 1 | Survival of three rat strains infected with aerosolized RVFV. Survival at each presented dose is shown. (A) Wistar-Furth, (B) ACl, and (C) Lewis. (D) Shows the probit curves for each rat strain, from which the LD 50 was determined.

the exposure chamber to $>60 \%$; the chamber humidity was controlled and monitored by the AeroMP system. Aerosol sampling was done via an all-glass impinger (AGI; Ace Glass, Inc., Vineland, NJ) operating at 6 liters per minute (lpm) which was connected to the exposure chamber. Aerosol samples were collected in $10 \mathrm{ml}$ of DMEM containing 2\% FBS and antifoam. The aerosol concentration of virus was determined by plaque assay on the contents of the AGI. The concentration of virus in the aerosol was calculated by multiplying the concentration of virus in the AGI by the volume of media in the AGI $(10 \mathrm{ml})$ and dividing that product by the product of the flow of air through the AGI $(6 \mathrm{lpm})$ and the duration of the exposure (10 min) (Roy and Pitt, 2005). The presented dose delivered to each rat was determined as previously described (Reed et al., 2007). First, the minute volume of the rat was calculated using Guyton's formula which is based on the animal's weight (Guyton, 1947). Presented dose was then determined by multiplying the aerosol concentration of RVFV by the duration of the exposure and minute volume.

\section{RESULTS}

\section{WISTAR-FURTH RATS DEVELOP HIGHLY LETHAL DISEASE AFTER AEROSOL EXPOSURE TO RVFV}

Wistar-Furth (WF) rats were exposed to aerosolized RVFV at four different doses, ranging from less than one calculated pfu/rat up
Table 2 | Relative comparison of clinical signs in rat strains after aerosol exposure to RVFV.

\begin{tabular}{|c|c|c|}
\hline $\begin{array}{l}\text { Clinical } \\
\text { parameter }\end{array}$ & Wistar-Furth & $\mathrm{ACl}$ \\
\hline
\end{tabular}

Fever (in rats $\quad$ Yes, $+1-2^{\circ} \mathrm{C} \quad$ Yes, $+2-3^{\circ} \mathrm{C} \quad$ Yes, $+2-3^{\circ} \mathrm{C}$ that died)

$\begin{array}{llll}\text { Fever No Nos } & \text { Nos }\end{array}$

(in surviving rats)

$\begin{array}{lll}\text { Weight loss } \quad 5-20 \% & 10-20 \% & 3-8 \%\end{array}$

(in rats that died)

Weight loss None Yes Yes

(in surviving rats)

$\begin{array}{llll}\text { Porphyrin } & + & ++ & + \\ \text { staining* } & & +\end{array}$

$\begin{array}{llll}\text { Ruffled fur } & + & + & +\end{array}$

Hunched posture $\quad+\quad++\quad++$

$\begin{array}{llll}\text { Neurological } & - & & +++\end{array}$

signs**

* Porphyrin staining occurs around the eyes/nose/mouth in response to stress or severe illness.

**Neurological signs included circling or rolling in cage, head tilt, unsteady gait. 
to $240 \mathrm{pfu} / \mathrm{rat}$ (Table $\mathbf{1}$ ). The rats were monitored daily for clinical illness, weight loss, and fever response using an implanted temperature transponder. Similar to previous studies using parenteral routes of infection and one prior report describing respiratory infection (Peters and Slone, 1982; Anderson et al., 1987, 1991a; Bird et al., 2007), WF rats were extremely sensitive to RVFV after aerosol exposure (Figure 1A). The number of deaths in each dose group and the average time to death of moribund rats is shown in Table 1. The $\mathrm{LD}_{50}$ of aerosolized RVFV in WF rats was 2 pfu (Table 1), as calculated using probit analysis (Figure 1D). This is similar to the published $\mathrm{LD}_{50}$ of RVFV in WF rats after subcutaneous or aerosol infection (1-5 pfu) (Peters and Anderson, 1981; Anderson et al., 1991a,b).

WF rats that succumbed to infection within the first week exhibited minimal outward signs of infection (summarized in Table 2). Ruffled fur was observed but minimal; some also exhibited a slight hunched posture before the terminal event. Rats that succumbed to infection lost weight relative to controls and survivors; weight loss was most striking in the rats that were exposed to the lower doses and succumbed after day 5 post-infection
(Figure 2, red lines). Rats in the highest dose group died or were euthanized by day 4 post-infection and lost relatively little weight (5-7\%). Some moribund WF rats had red porphyrin staining around the eyes or nose (Figure 7). Most of the rats that succumbed to infection also had a spike in body temperature $1-2^{\circ}$ above baseline that occurred within the last $12 \mathrm{~h}$ prior to death (Figure 3). In some rats, the spike in body temperature was followed by a sharp decline right before death. None of the surviving WF rats displayed fever responses during the course of infection.

Tissues from the infected rats obtained on necropsy at the time of death or euthanasia were analyzed for viral load by plaque assay, and infectious virus was found widespread throughout many tissues (Figures 4A-F). The highest levels of infectious virus were found in the liver and spleen, but $6-7 \log _{10}$ pfu were also seen in the lung. The lung is typically not thought of as a target tissue for RVFV, but clearly inhalation of the virus results in high levels of virus replication even several days after exposure at the time of death (Figure 4B). Between 5 and $6 \log _{10}$ pfu were found in heart and kidney tissue of most but not all rats. Despite not showing neurological impairment, most of
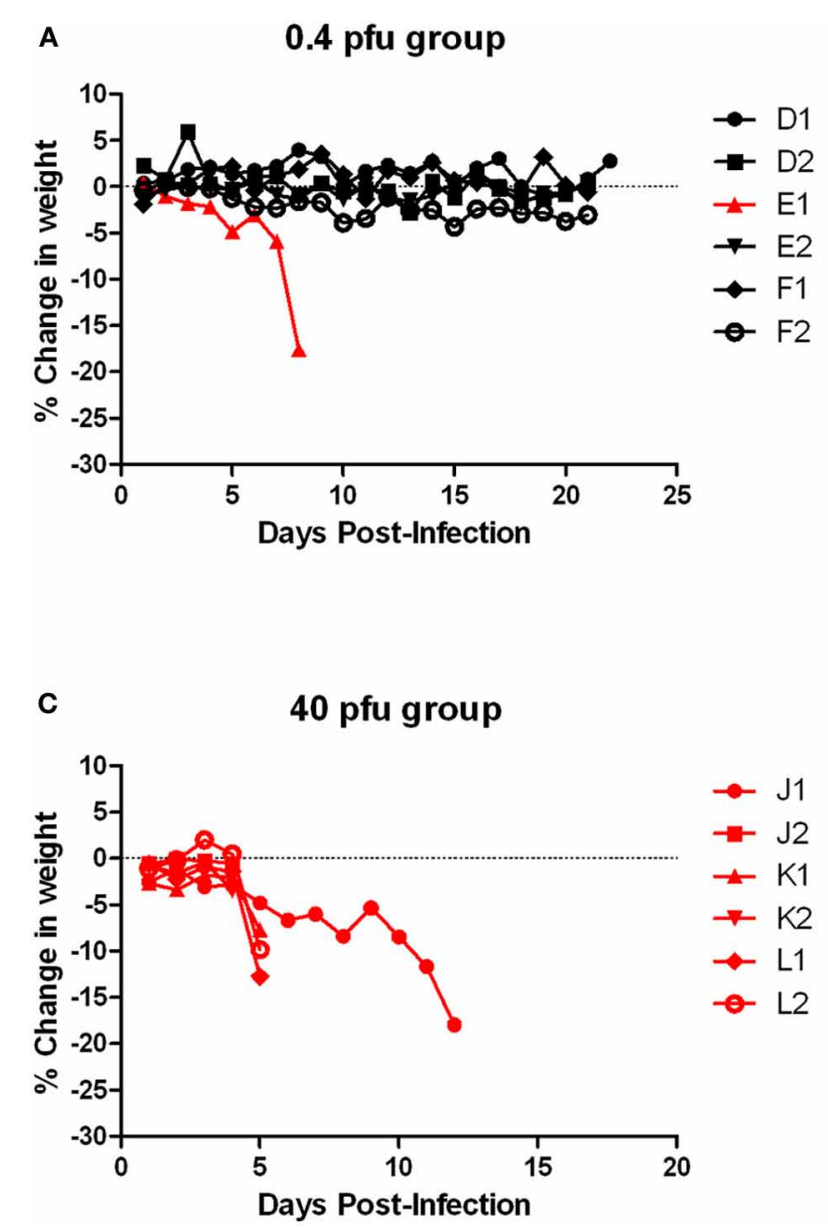

FIGURE 2 | Body weight of Wistar-Furth rats infected with aerosolized RVFV. Groups of six female Wistar-Furth rats were infected with RVFV by the aerosol route at four doses plus uninfected controls. (A) $0.4 \mathrm{pfu} / \mathrm{rat}$; (B) 5 pfu/rat; (C) 40 pfu/rat; (D) 240 pfu/rat. The $y$-axis of each graph
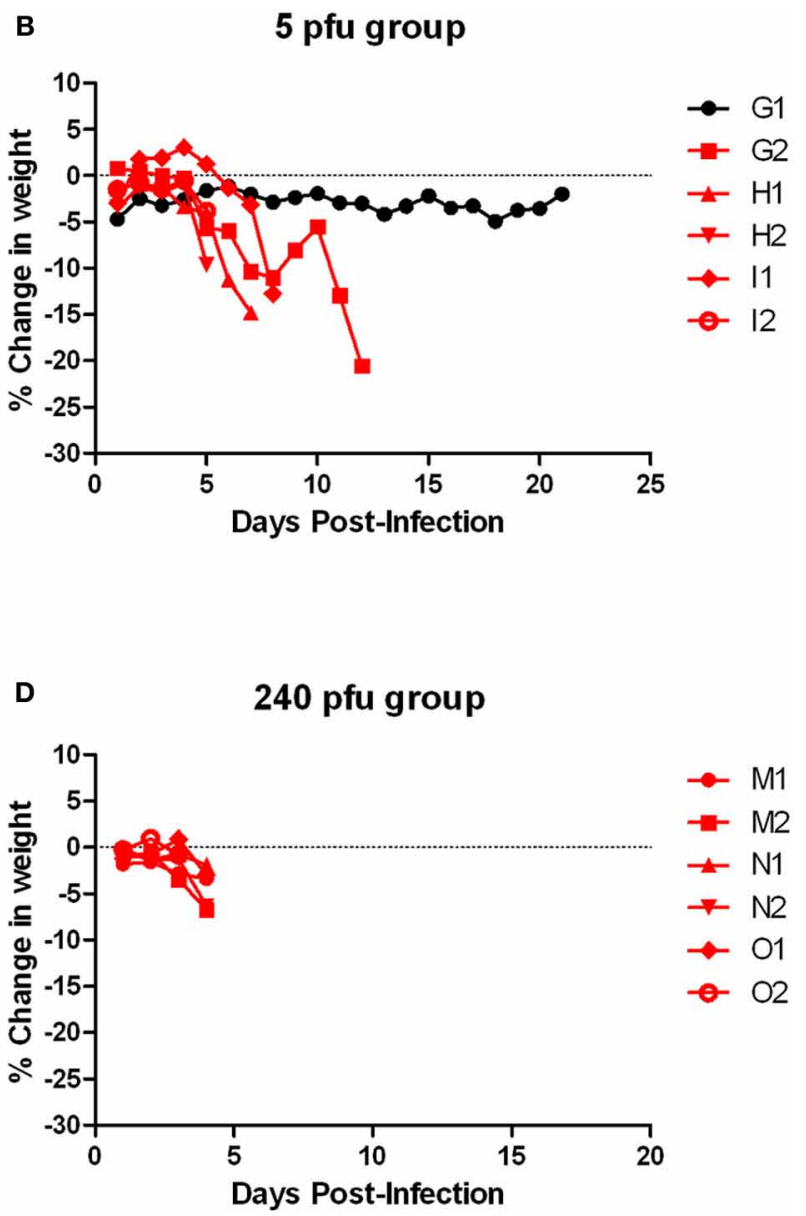

displays the change in weight of individual animals relative to the average weight of the uninfected control rats $(n=6)$. Rats that succumbed to infection are shown in red; rats that survived are shown in black. 


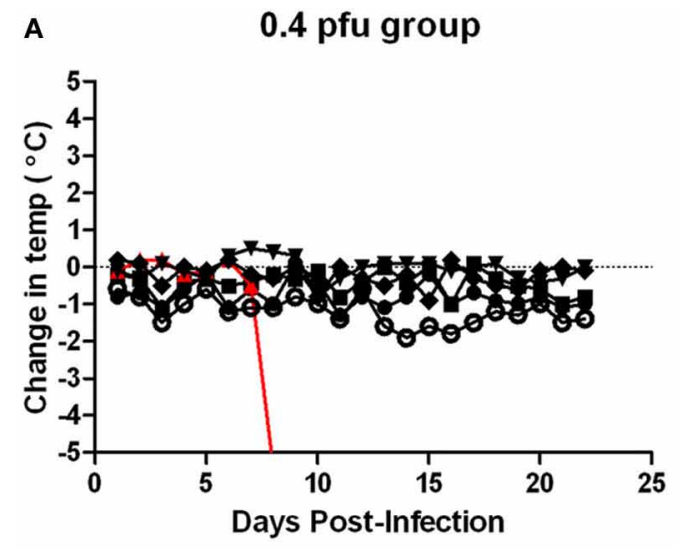

C

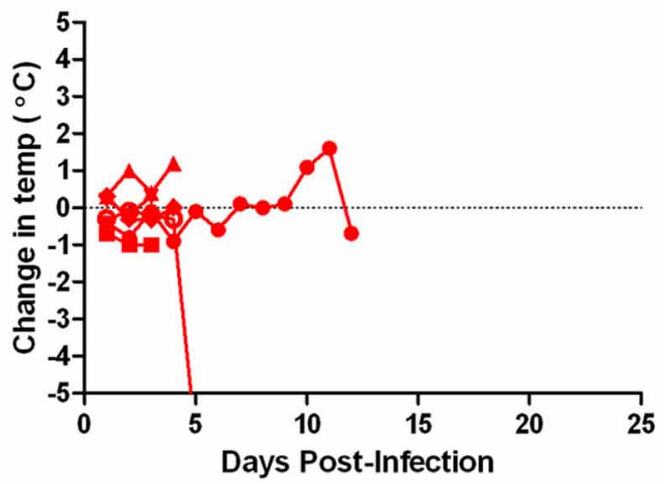

E

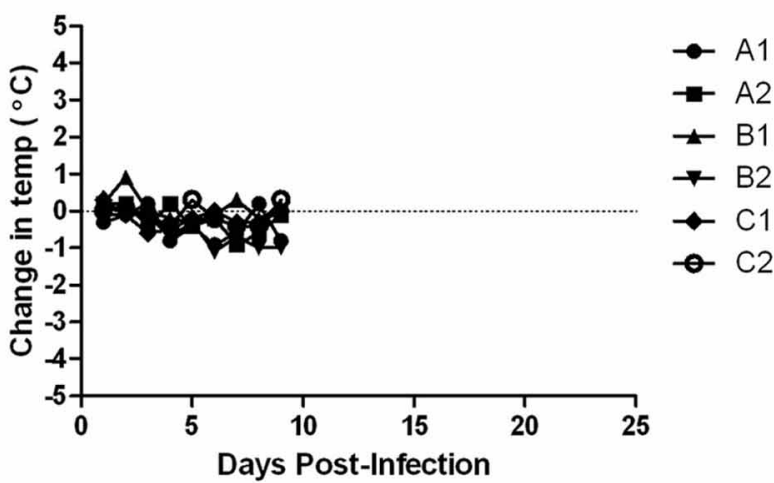

FIGURE 3 | Body temperature of Wistar-Furth rats infected with aerosolized RVFV. Groups of six female Wistar-Furth rats were infected with RVFV by the aerosol route at four doses plus uninfected controls. (A) $0.4 \mathrm{pfu} / \mathrm{rat}$; (B) $5 \mathrm{pfu} / \mathrm{rat}$; (C) $40 \mathrm{pfu} / \mathrm{rat}$; (D) 240 pfu/rat; (E) uninfected
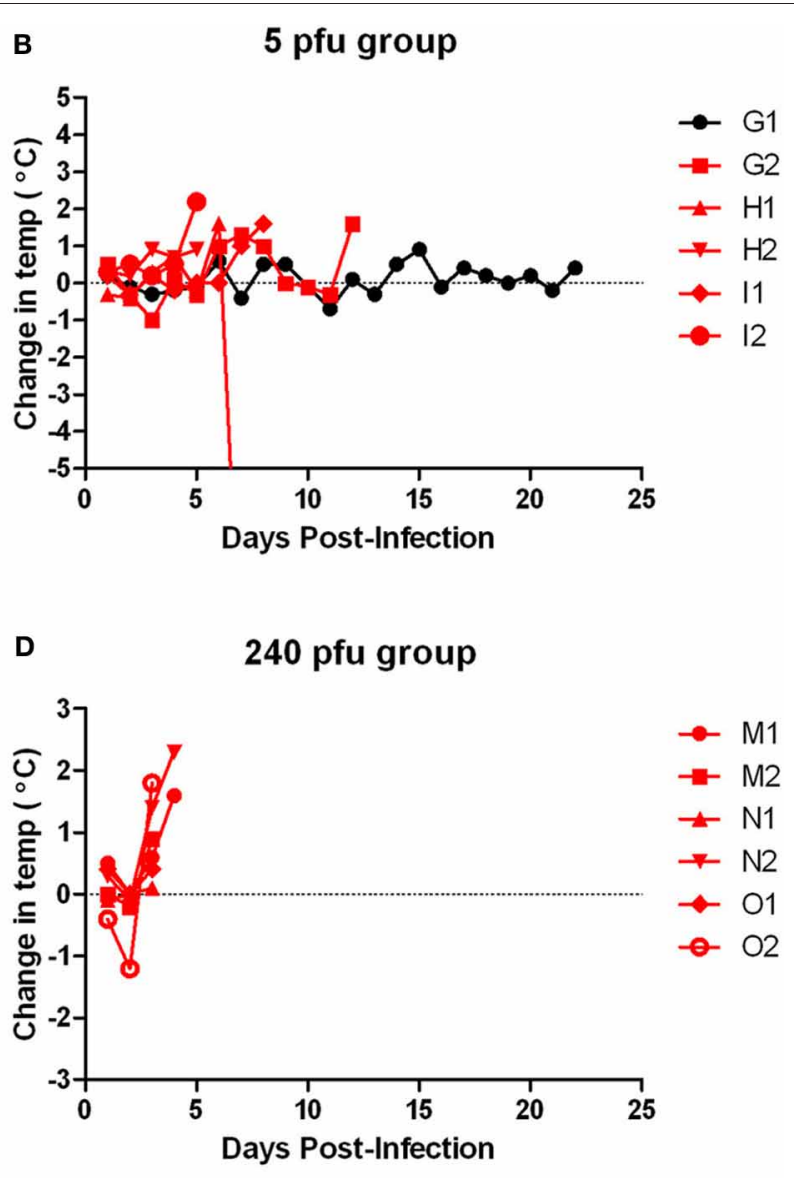

control rats. The $y$-axis of each graph displays the change in body temperature of individual rats relative to their temperature on the day of infection. Rats that succumbed to infection are shown in red; rats that survived are shown in black. the WF rats had $3-5 \log _{10}$ pfu in brain tissue. Rats that were exposed but survived infection had no detectable virus in any tissues at the time of euthanasia (22 d.p.i.; data not shown). The presented dose that the rats received did not have a significant correlation with the amount of infectious virus found in the tissues.
In summary, WF rats were highly susceptible to aerosolized RVFV. The rapidly progressing disease in this strain of rat occurred in a similar time frame as previously published parenteral infection, and the $\mathrm{LD}_{50}$ after aerosol was also similar to previous publications (Anderson and Peters, 1988; Anderson et al., 1991a; summarized in Table 3). 
Bales et al.

Inhalational RVF in rats

ACI RATS DEVELOP NEUROLOGICAL DISEASE AFTER AEROSOL EXPOSURE TO RVFV

Limited historical data suggested that ACI rats infected subcutaneously with high doses of RVFV $\left(10^{3}-10^{5} \mathrm{pfu} / \mathrm{rat}\right)$ displayed neurological signs, and $10-50 \%$ of them succumbed to infertron between 9 and 15 days post-infection (Bucci et al., 1981; Peters and Clone, 1982). To determine if inhalation of RVFV results in a similar disease outcome, female ACI rats were exposed to aerosolized RVFV at presented doses ranging from less than $1 \mathrm{pfu} / \mathrm{rat}$ up to $3900 \mathrm{pfu} / \mathrm{rat}$ (Figure 1B and Table 1). ACI rats were monitored for clinical illness, weight loss, and fever. Using probit analysis, the $\mathrm{LD}_{50}$ of RVFV in ACI rats was 123 pu (Figure 1D). ACI rats infected with RVFV by aerosol at the two highest doses (3900 and $250 \mathrm{pfu}$ ) died between 6 and 8 days post-infection (Table 1). Three later deaths (day 13-14 postinfection) were seen at the lower doses (Figure 1B).
A

Wistar-Furth: Liver

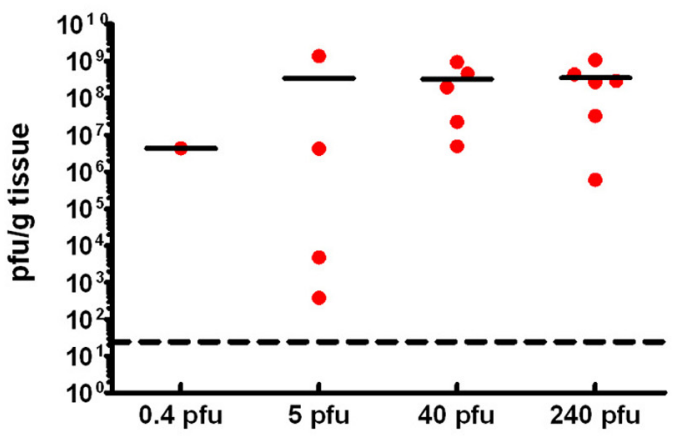

C

Wistar-Furth: Spleen

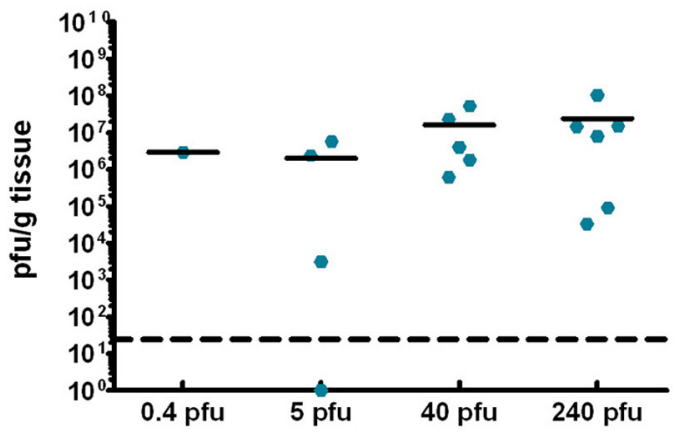

E

Wistar-Furth: Heart

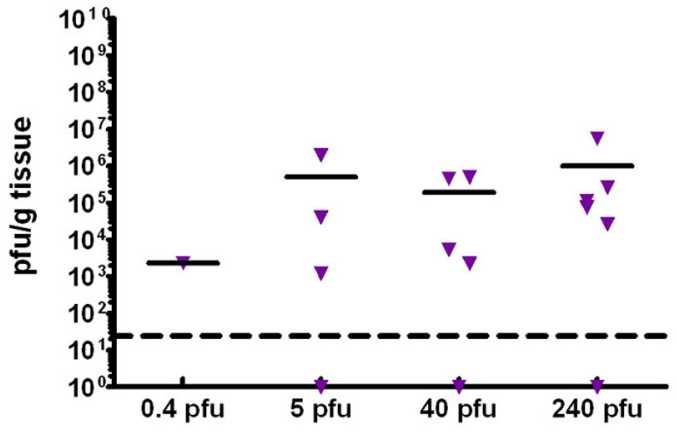

- Spleen

D
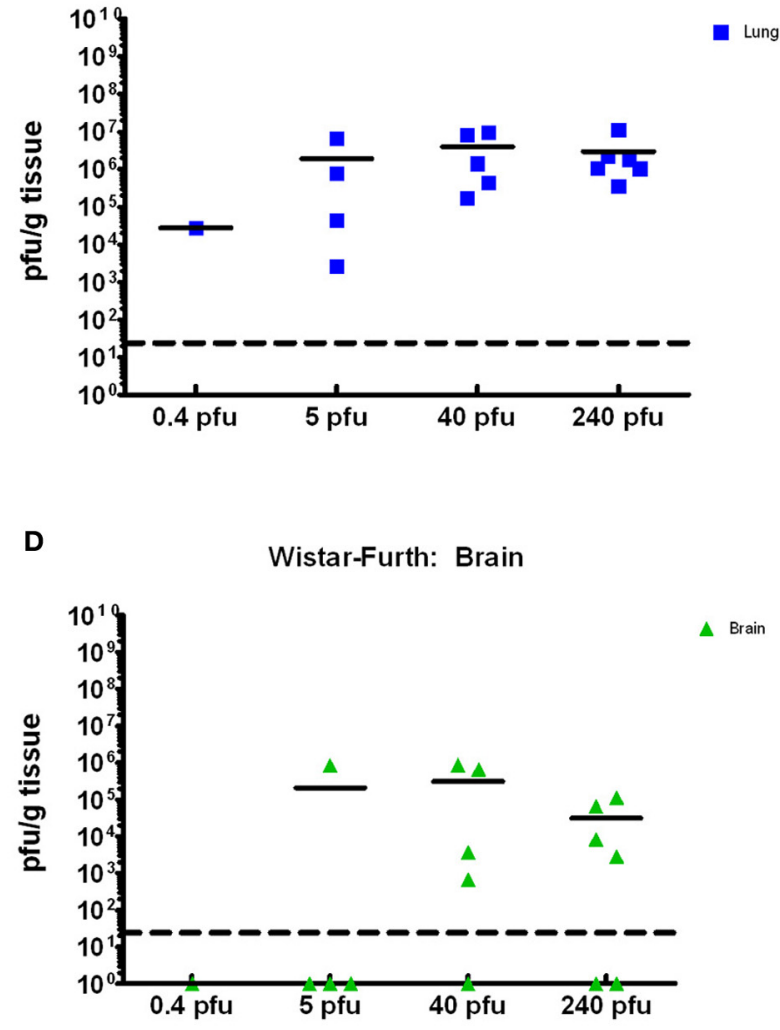

$\mathbf{F}$

$\nabla$ Heart

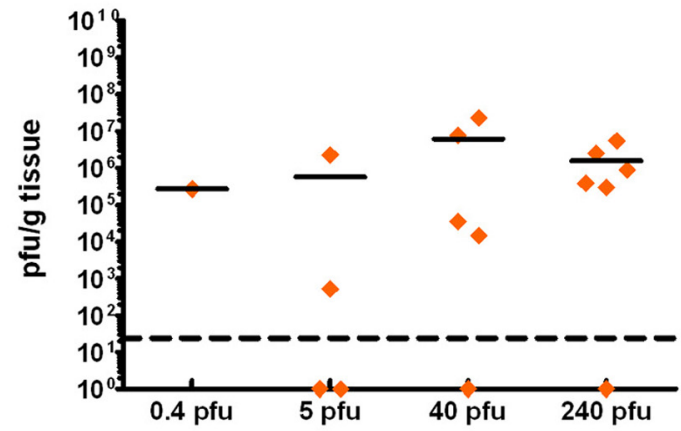

FIGURE 4 | Continued

Frontiers in Cellular and Infection Microbiology

www.frontiersin.org

August 2012 | Volume 2 | Article 105 | 6 


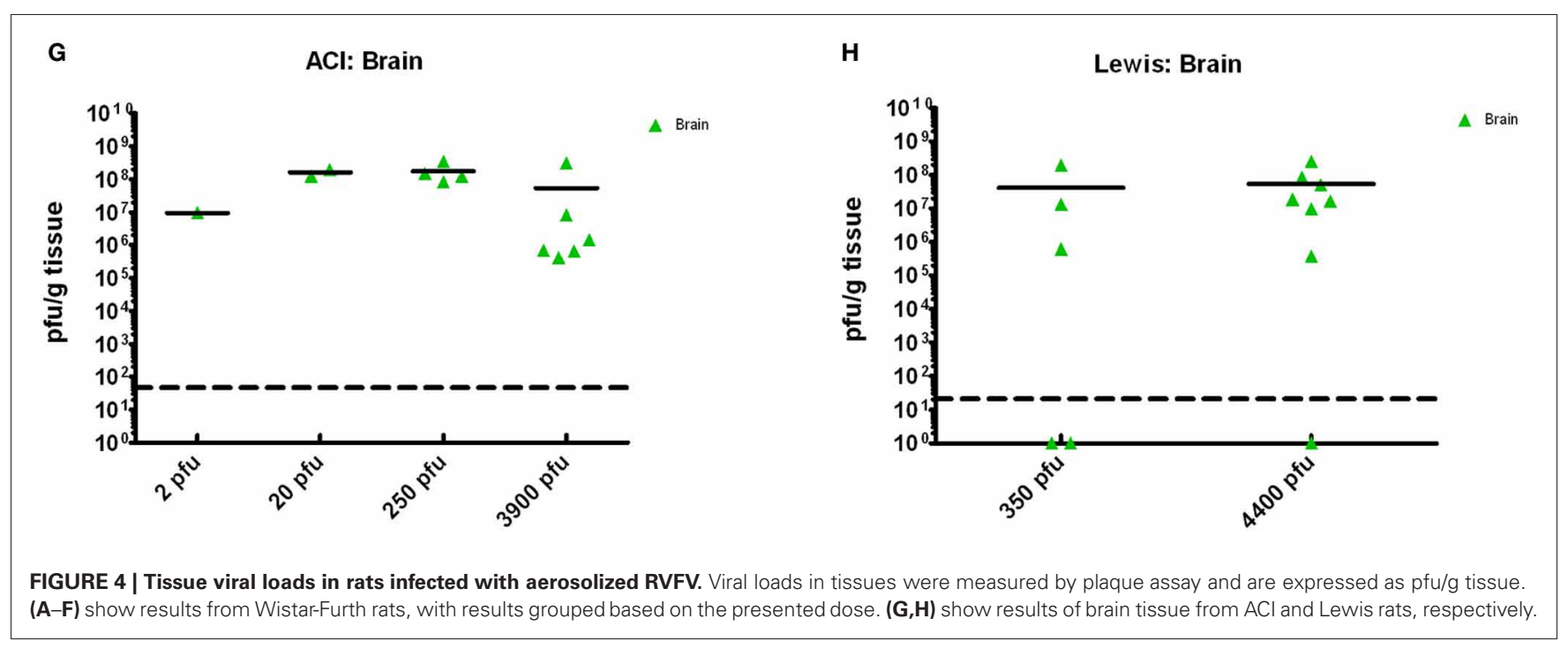

Table 3 | Comparison of disease outcome of different rat strains after subcutaneous or aerosol exposure to RVFV.

\begin{tabular}{|c|c|c|c|c|c|c|}
\hline Rat strain & Dose (pfu) & \multicolumn{2}{|c|}{ Subcutaneous* } & \multicolumn{2}{|c|}{ Aerosol } & Comparison S.C. vs. Aerosol \\
\hline Wistar-Furth & $10^{3}$ & 90 & 3 & 100 & 4 & $\begin{array}{l}\text { Severe hepatic disease; similar time } \\
\text { frame and clinical signs }\end{array}$ \\
\hline $\mathrm{ACl}$ & $10^{3}$ & 10 & 15 & 100 & 6 & $\begin{array}{l}\text { Neurological disease; similar clinical } \\
\text { signs; shorter time frame and } \\
\text { increased lethality by aerosol }\end{array}$ \\
\hline Lewis & $10^{3}$ & 0 & $N / A$ & 100 & 7 & $\begin{array}{l}\text { High lethality at modest doses by } \\
\text { aerosol }\end{array}$ \\
\hline
\end{tabular}

* Subcutaneous exposure data from Peters and Slone (1982).

Moribund ACI rats had apparent neurological signs, including head tilt, rolling in cage, and instability (Table 2 ). Rats that succumbed to infection had a decrease in body weight and a $2-3^{\circ} \mathrm{C}$ temperature spike followed by a drop in temperature prior to death/euthanasia (Figures 5 and 6). Surviving rats also did not gain as much weight as control animals, even at the lowest dose (Figure 5A). Several rats that survived infection also had a transient fever; however, none of the survivors displayed neurological signs.

Porphyrin secretion by the lacrimal gland behind the eye can be indicative of severe illness or stress. Most of the moribund ACI rats exhibited dramatic porphyrin staining around the eyes and/or mouth during end-stage disease prior to death/euthanasia (Figure 7). Extensive porphyrin staining along with other clinical parameters (neurological distress, weight loss, fever) was an important criterion for euthanasia in all three strains of rat.

Tissues from the infected ACI rats were analyzed for viral load by plaque assay (Figure 4G). High levels of virus $\left(6-8 \log _{10} \mathrm{pfu}\right)$ were found in brain tissue from all moribund or neurologically distressed rats. However, virus was undetectable in all other tissues tested, including blood, liver, spleen, lung, kidney, and heart (data not shown). Rats that survived infection, including those with a measurable spike in temperature, had no detectable virus in any tissues at the time of euthanasia ( 28 d.p.i.). As was seen with the WF rats, the presented dose that the rats received did not have a significant correlation with the amount of infectious virus found in brain tissue.

In review, ACI rats developed a fever and neurological disease after aerosol infection with RVFV, and the brain was the main tissue targeted for viral replication at end-stage disease. While the neurological signs seen in the ACI rats were similar to what has been documented for parenteral infection (Bucci et al., 1981), the overall lethality was increased after inhalational exposure (100\% vs. $10-50 \%$, respectively, at comparable doses) and death occurred in a shorter time frame than s.c. infection (6-8 days vs. 9-15 days, respectively; summarized in Table 3).

\section{LEWIS RATS ALSO DEVELOP NEUROLOGICAL DISEASE AFTER AEROSOL EXPOSURE TO RVFV}

In two previously published reports, no deaths of Lewis rats were seen after parenteral infection with up to $5 \times 10^{5} \mathrm{pfu}$ of the ZH501 strain of RVFV (Peters and Anderson, 1981; Peters and Slone, 1982). A third study reported 17\% mortality of Lewis rats infected with $10^{5}$ pfu by the s.c. route (Anderson et al., 1987). 


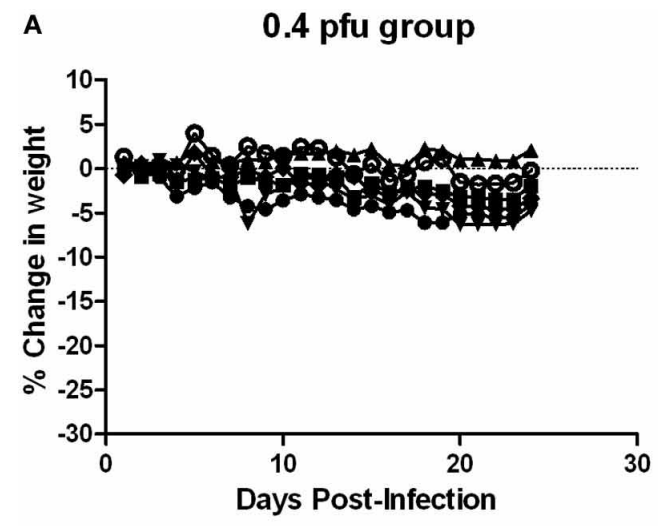

C

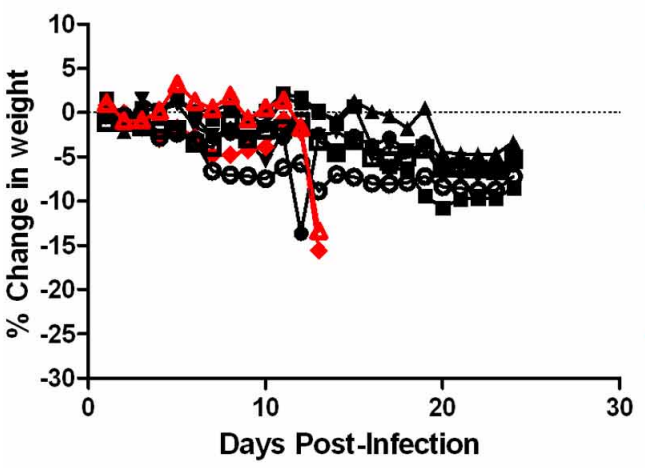

E

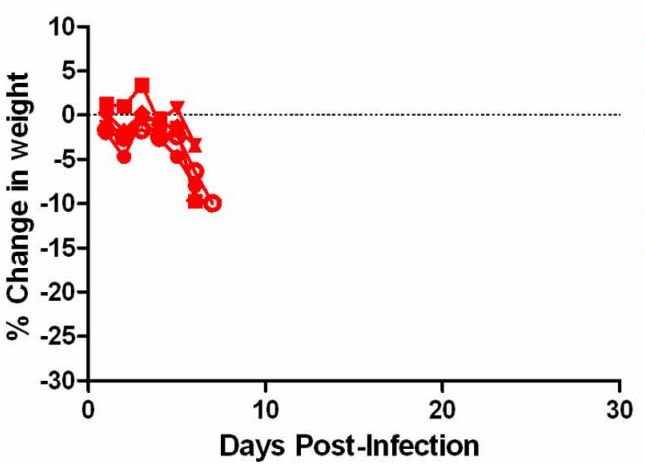

FIGURE 5 | Body weight of ACl rats infected with aerosolized RVFV. Groups of six to eight female $\mathrm{ACl}$ rats were infected with RVFV by the aerosol route at five doses plus uninfected controls. (A) 0.4 pfu/rat;

(B) 2 pfu/rat; (C) 20 pfu/rat; (D) 250 pfu/rat; (E) 3900 pfu/rat. The $y$-axis

Similar to what was done with the Wistar-Furth and ACI rats described above, female Lewis rats were exposed to aerosolized RVFV at presented doses ranging from 1.5 to 4400 pfu (Table 1). Unexpectedly, $8 / 8$ rats died at a dose of $4400 \mathrm{pfu}$ and 5/6 rats died at a dose of 350 pfu, all between 6 and 9 days after infection (Figure 1C). No other deaths were observed in the lower dose groups. By probit analysis, the $\mathrm{LD}_{50}$ was calculated to be $112 \mathrm{pfu}$ (Figure 1D and Table 1).
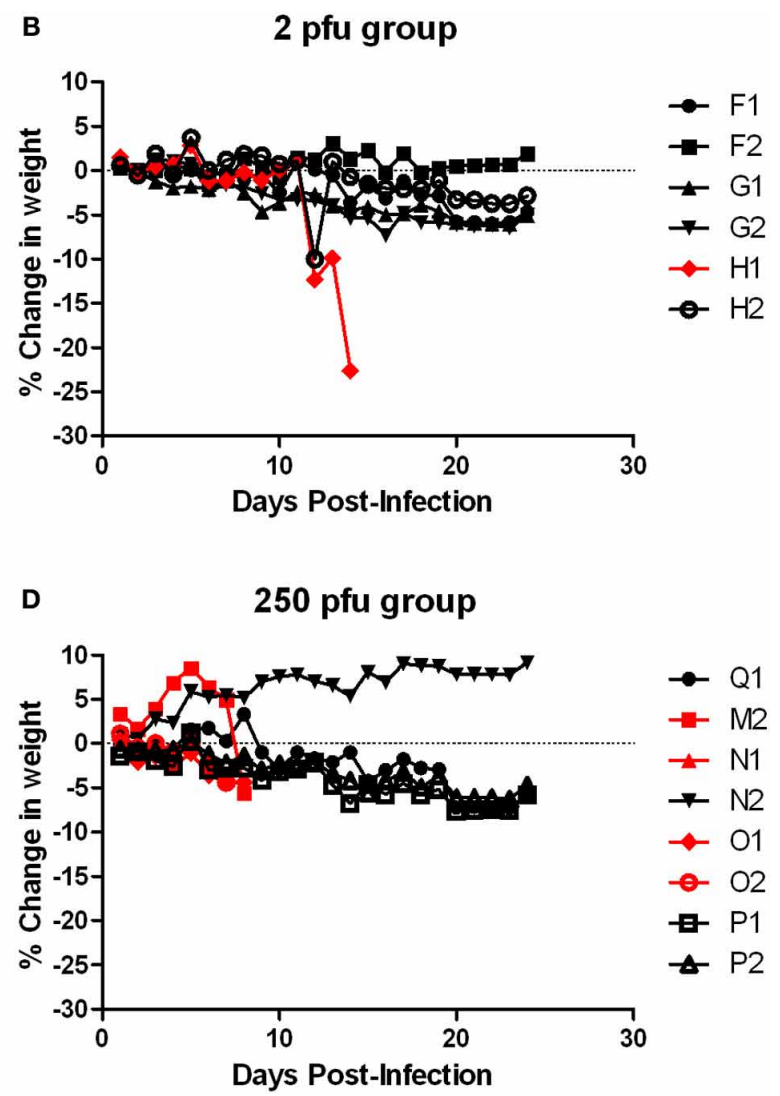

of each graph displays the change in weight of individual animals relative to the average weight of the uninfected control group $(n=4)$. Rats that succumbed to infection are shown in red; survivors are shown in black.

Similar to the ACI rats, moribund Lewis rats had neurological signs, including head tilt, rolling in cage, and instability (Table 2 ). Lewis rats that succumbed to infection had a moderate decrease in body weight ( $8 \%$ maximum compared to $10-20 \%$ decrease in $\mathrm{ACI}$ rats) and a $2-3^{\circ} \mathrm{C}$ temperature spike prior to death/euthanasia (Figures 8 and 9). Unlike what was seen in the ACI rats, there were no dramatic temperature spikes in Lewis rats that survived. Porphyrin staining was also 


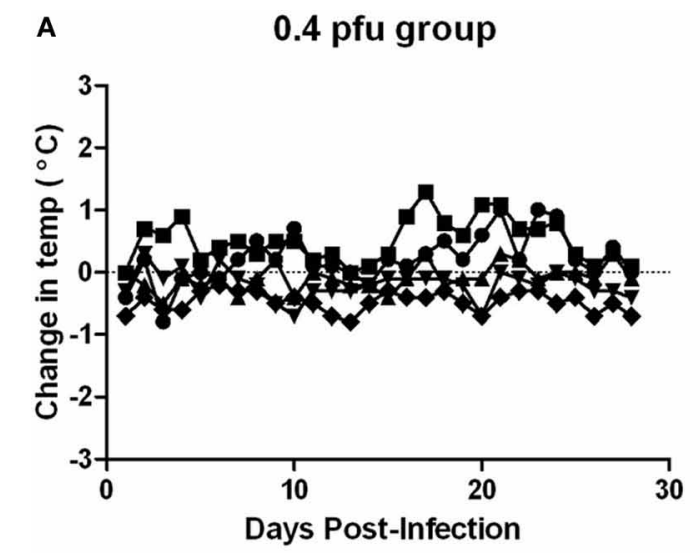

C

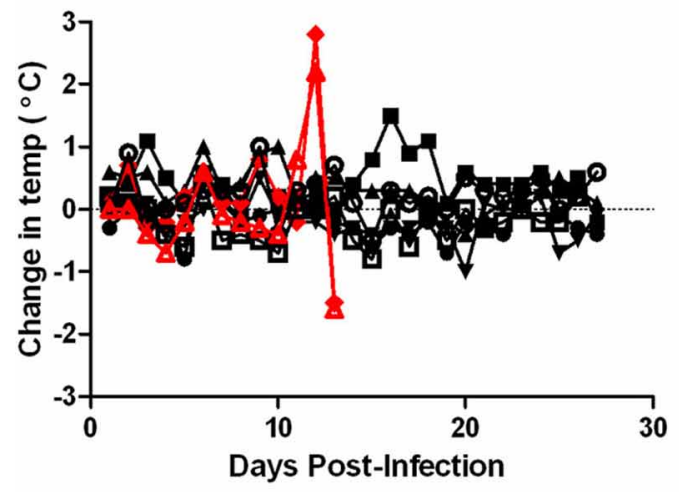

E

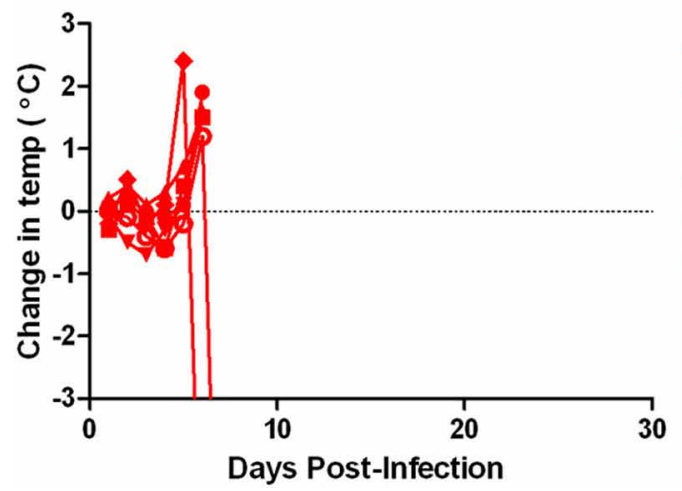

FIGURE 6 | Body temperature of $\mathrm{ACl}$ rats infected with aerosolized RVFV. Groups of six to eight female ACl rats were infected with RVFV by the aerosol route at five doses plus uninfected controls. (A) $0.4 \mathrm{pfu} / \mathrm{rat}$; (B) 2 pfu/rat; (C) 20 pfu/rat; (D) 250 pfu/rat; (E) 3900 pfu/rat; (F) Uninfected
B 2 pfu group

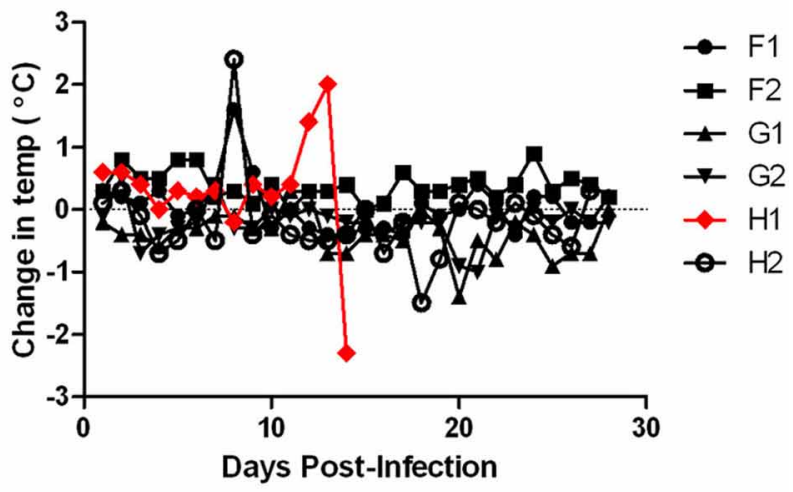

D 250 pfu group

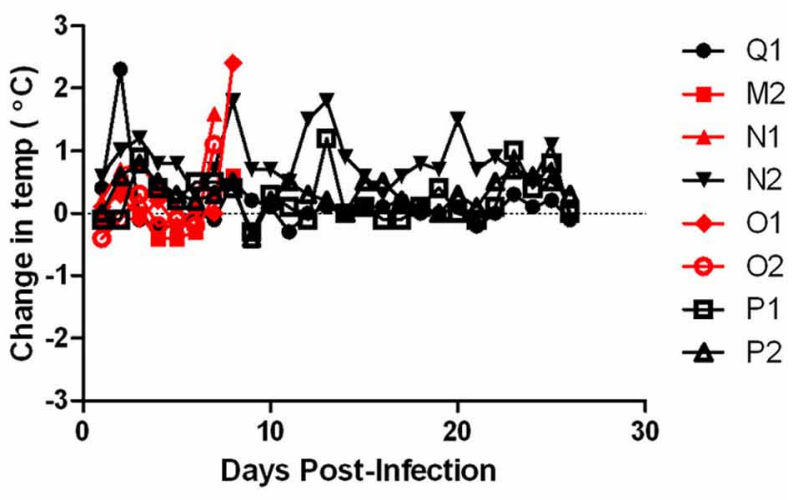

F Control group

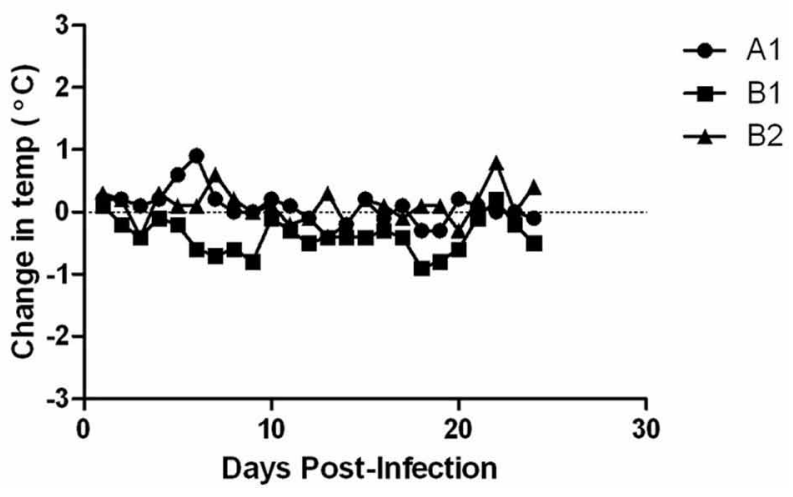

control rats. The $y$-axis of each graph displays the change in body temperature of individual animals relative to their temperature on the day of infection. Rats that succumbed to infection are shown in red; survivors are shown in black. seen in moribund Lewis rats, but to a lesser degree than the ACI rats.

Tissues from the infected Lewis rats were analyzed for viral load by plaque assay (Figure $4 \mathbf{H}$ ). The results were similar to those found for the ACI rats. Very high levels of virus (6-8 $\log _{10} \mathrm{pfu}$ ) were found in brain tissue from all moribund rats exhibiting neurological distress. Virus was undetectable in all other tissues. Surviving rats also had undetectable levels of virus in tissues and blood.

Because the deaths seen here in the Lewis rats were contradictory to previously published reports using s.c. infection with RVFV strain ZH501, a cohort of five Lewis rats were infected s.c. 

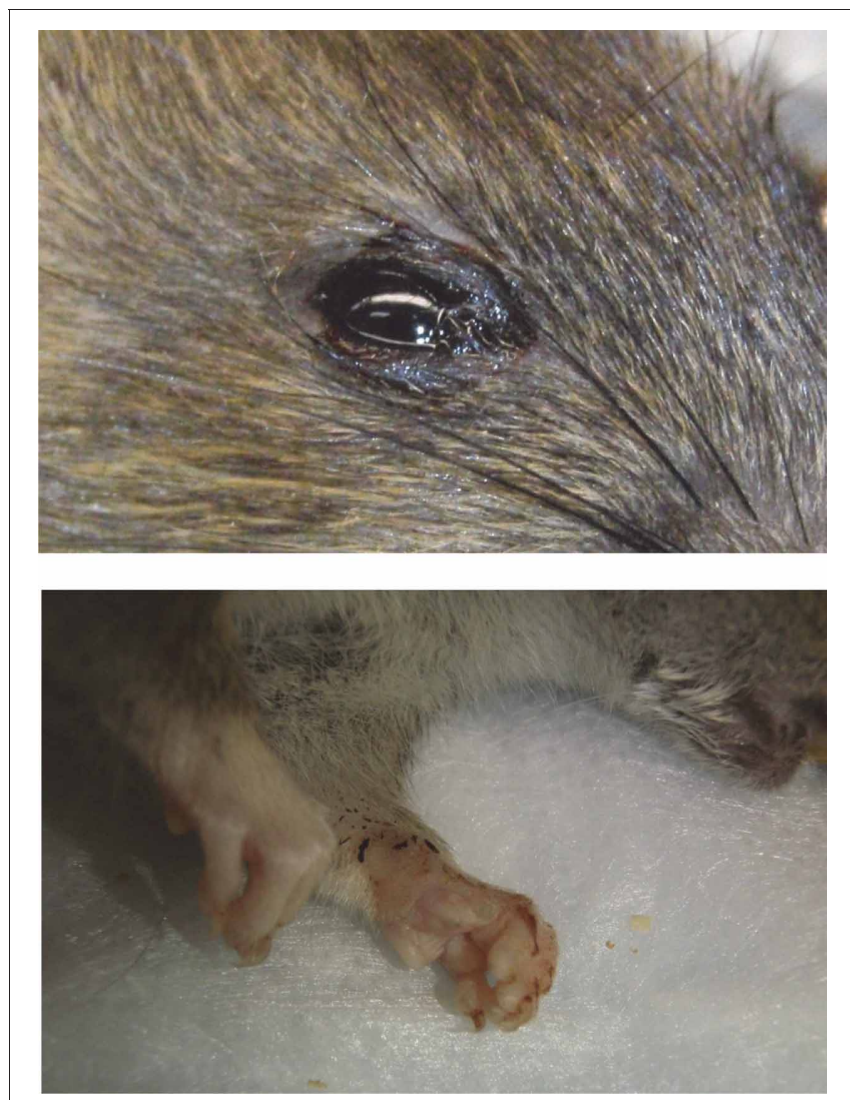

FIGURE 7 | Example of porphyrin staining in $\mathrm{ACl}$ rats.

Chromodacryorrhea (dried porphyrin) on the eye and paw of $\mathrm{ACl}$ rat $\mathrm{H} 1$ immediately prior to euthanasia (14 d.p.i.).

with a comparable dose of RVFV (2750 pfu). All rats survived with no clinical signs of infection, including weight loss or fever (Figure 10, blue line), confirming that in our hands Lewis rats are resistant to death after s.c. infection in accordance with the previous reports.

The Lewis rats that survived the subcutaneous infection were then re-challenged with RVFV by aerosol 28 days after the initial s.c. exposure. Of the five rats re-challenged, four of them died with similar neurological signs and within a similar time frame (6-7 days) as the aerosol-only Lewis rats (Figure 10A, green line). Fever and weight loss were noted in the four re-challenged rats (Figures 10B,C). The one rat that survived re-challenge did not display clinical signs or fever, but did have transient weight loss between days 13 and 15 after re-challenge. Thus, prior s.c. infection did not provide protection of Lewis rats from aerosol challenge with the homologous virus.

In review, Lewis rats displayed unexpected lethality after inhalation of modest doses of RVFV (summarized in Table 3). Fever and neurological signs were similar to that seen with ACI rats, and brain tissue was the main target of viral replication at end-stage disease. The reasons for the discrepancy between s.c. and aerosol outcome of Lewis rats are currently under investigation.

\section{DISCUSSION}

RVFV is one of many pathogens for which there is concern because of its potential use as a biological weapon (Department of Health and Human Services, 2005; United States Department of Agriculture, 2005). MCMs that can protect against RVFV, particularly after aerosol exposure, are urgently needed. Because there are insufficient numbers of confirmed human cases resulting from aerosol exposure to RVFV, experimental studies in relevant animal models would aid in determining whether altering the route of infection would result in differences in the human clinical disease. Licensure of MCMs against RVFV will require using the Animal Efficacy Rule of the U.S. Food and Drug Administration (FDA), which allows for a demonstration of product efficacy in one or more well-characterized animal models which are considered relevant to the disease in humans (Food and Drug Administration, 2002). The FDA requires that studies done under the Animal Efficacy Rule to support licensure of a product against inhalational exposure must include an aerosol challenge. The goal of the experiments reported here was to evaluate the impact of aerosol infection upon the disease course and outcome of inhaled RVFV in different inbred rat strains.

By fortuitous circumstance, different inbred rat strains developed different disease outcomes after s.c. inoculation with RVFV that resemble the spectrum of human disease (Bucci et al., 1981; Peters and Slone, 1982; Anderson et al., 1987). Of the three rat strains, only data in Wistar-Furth rats has been reported previously for aerosol exposure. Anderson et al. (1991a) reported that the $\mathrm{LD}_{50}$ for Wistar-Furth rats was 1 pfu by the aerosol route, which is comparable to what has been reported for s.c. inoculation (Anderson and Peters, 1988). Because it had been more than two decades since the previous report was published describing aerosol challenge of Wistar-Furth rats, our first goal was to determine whether there had been any appreciable change in the lethality of ZH501 in Wistar-Furth rats. Probit analysis of the survival studies found no difference in the $\mathrm{LD}_{50}$ from prior estimates for aerosol exposure or s.c. inoculation (Tables $\mathbf{1}$ and $\mathbf{3}$ ). Also in agreement with the results from the prior studies, Wistar-Furth rats succumbed due to a rapidly progressing severe disease, and the time to death was similar (2-8 days).

This study represents the first known report of an $L_{50}$ of RVFV in ACI rats by any route of infection. The $\mathrm{LD}_{50}$ in ACI rats after aerosol exposure was 100-fold greater than that of WistarFurth rats (123 pfu vs. 2 pfu, respectively), which highlights the differences in susceptibility to severe disease exhibited by the two inbred strains of rat. At the highest presented doses, the ACI rats lived several days longer than the WF rats, and they displayed significant clinical neurological signs. Aerosol exposure of ACI rats resulted in $100 \%$ lethality at 3900 pfu within 6 d.p.i. This is a much higher lethality and shorter survival time than previous studies with s.c. inoculation which found $10 \%$ mortality at a dose of $10^{3}$ pfu and $50 \%$ mortality at $10^{5}$ pfu within $15-16$ d.p.i. (Peters and Slone, 1982). While the clinical disease did not change with aerosol exposure reported in our study, the disease course was shortened and the rats were more susceptible to lower doses of virus when delivered via aerosol (Table 3).

Three previously published reports showed little (17\%) to no $(0 \%)$ mortality of Lewis rats after parenteral infection with 

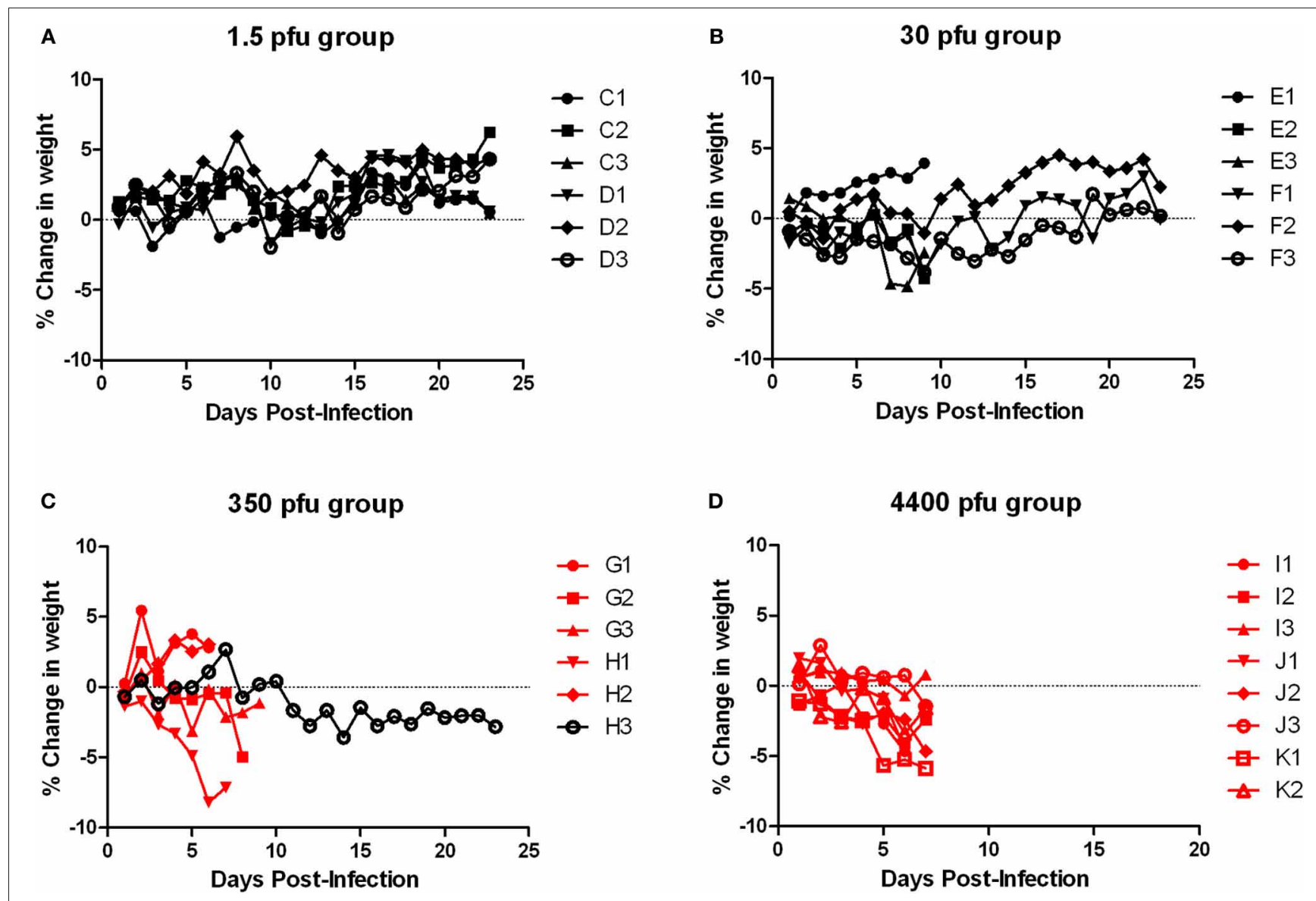

FIGURE 8 | Body weight of Lewis rats infected with aerosolized RVFV. Groups of six to eight female Lewis rats were infected with RVFV by the aerosol route at four doses plus uninfected controls. (A) $1.5 \mathrm{pfu} / \mathrm{rat} ;$ (B) $30 \mathrm{pfu} / \mathrm{rat}$; (C) $350 \mathrm{pfu} / \mathrm{rat}$; (D) $4400 \mathrm{pfu} / \mathrm{rat}$. The

up to $5 \times 10^{5}$ pfu of the ZH501 strain of RVFV (Bucci et al., 1981; Peters and Slone, 1982; Anderson et al., 1987). In our hands, subcutaneous infection of Lewis rats with $2750 \mathrm{pfu}$ also resulted in $100 \%$ survival with no clinical signs. However, exposure of the Lewis rats to aerosol doses of 350 and $4400 \mathrm{pfu}$ resulted in 83 and $100 \%$ mortality, respectively. Clinical observations as well as virology results indicate that viral encephalitis similar to that seen in the ACI rats was induced by aerosol exposure of Lewis rats. It is curious why this change in clinical outcome occurs with Lewis rats while encephalitis is induced in ACI rats by either route. One possibility is that the virus may gain access to the central nervous system through the olfactory bulb during aerosol infection similar to other encephalitic viruses (Pratt et al., 2012). In support of this hypothesis, we also observed that Lewis rats that survived s.c. infection were not protected against subsequent re-challenge by aerosol exposure to the homologous virus. Similarly, Anderson et al. (1991a) reported that after vaccination of Wistar-Furth rats, some died of encephalitis instead of hepatic disease after aerosol exposure. The observed lack of protection from homologous virus by aerosol challenge may also have significant implications for development of MCMs to protect against inhalational exposure to RVFV. Further investigation is needed to understand these findings.

Inbred rat strains differ genetically in a number of biochemical markers (Bender et al., 1994), with more differences likely undiscovered. The outcome of RVFV infection in rats is clearly determined by the genetic background of the inbred rat strains, but it was not shown to be related to either cellular susceptibility to infection or to the major histocompatibility complex (Peters and Anderson, 1981). Breeding experiments conducted by Peters and Anderson (Peters and Anderson, 1981; Anderson et al., 1991b) demonstrated that a dominant gene determines resistance to the fatal liver infection after RVFV infection. However, similar experiments crossing rats susceptible to encephalitis with resistant rats have not been as clearly revealing, suggesting a more complex genetic component (Peters and Anderson, 1981). Others have shown that genetic drift of inbred rat strains at different breeding facilities between Europe and the United States can compound the issue (Ritter et al., 2000). Investigation into the influence of the genetic differences between rat strains will aid in understanding the differences in outcome we have observed. 

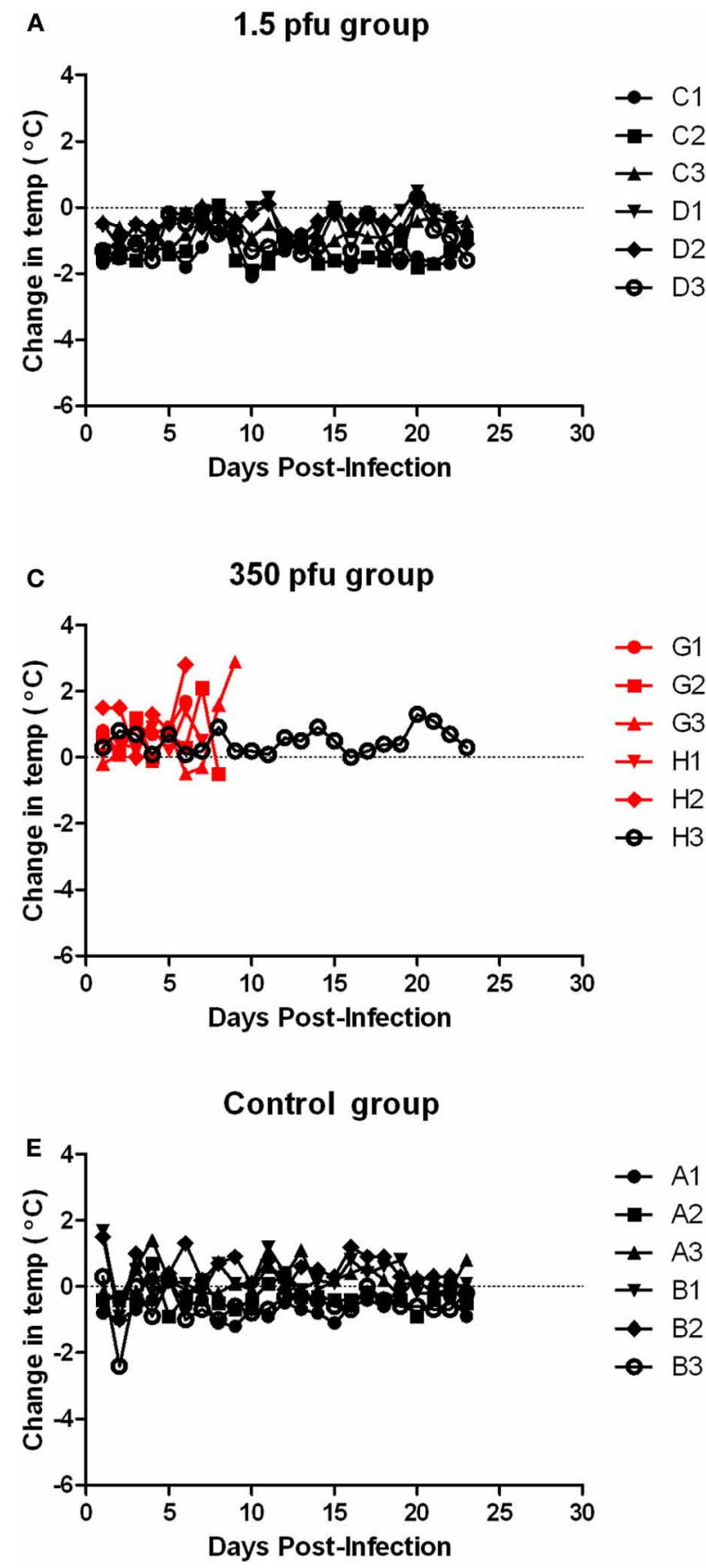

FIGURE 9 | Body temperature of Lewis rats infected with aerosolized RVFV. Groups of six to eight female Lewis rats were infected with RVFV by the aerosol route at four doses plus uninfected controls. (A) $1.5 \mathrm{pfu} / \mathrm{rat}$; (B) $30 \mathrm{pfu} / \mathrm{rat}$; (C) $350 \mathrm{pfu} / \mathrm{rat}$; (D) $4400 \mathrm{pfu} / \mathrm{rat}$; (E) Uninfected control
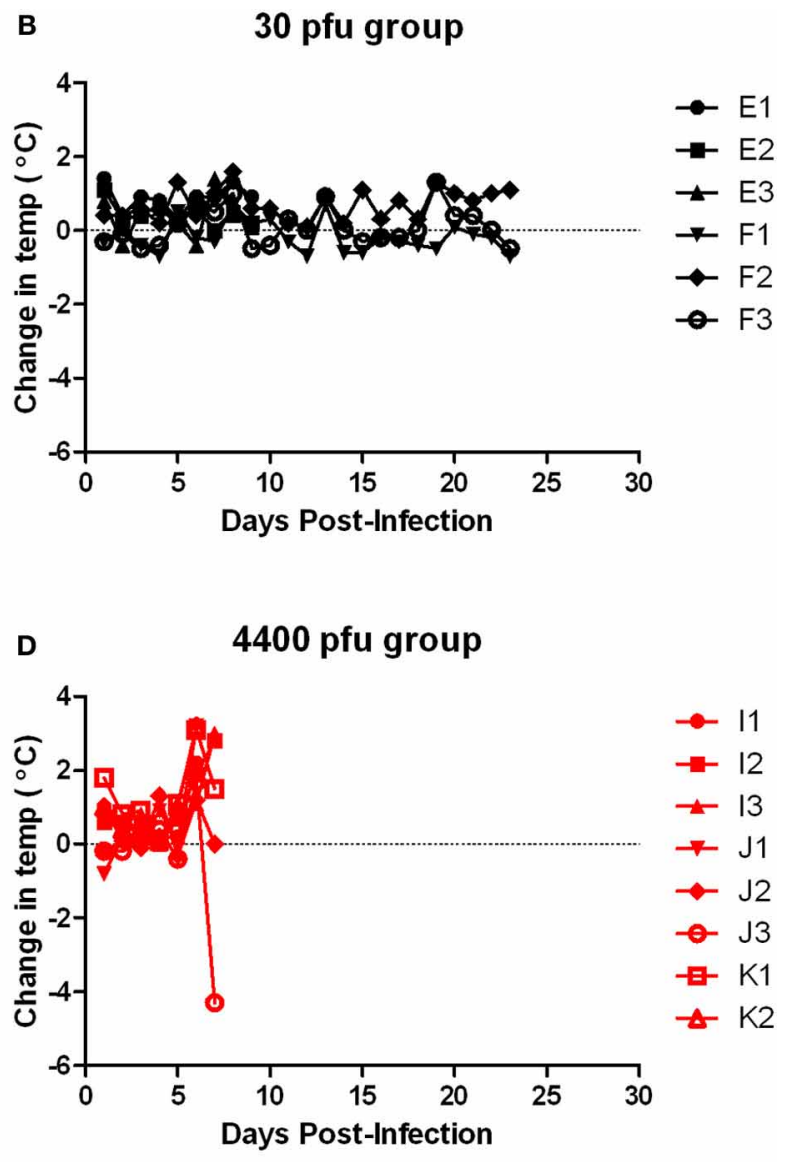

rats. The $y$-axis of each graph displays the change in body temperature of individual animals relative to their temperature prior to infection. Rats that succumbed to infection are shown in red; survivors are shown in black.
In all three strains of rat, we observed no correlation between the dose of virus the rats received and the level of infectious virus present in tissues at the time of necropsy. Rats of the same strain had similar levels of virus in tissues at time of death regardless of the input dose, even though lower presented doses resulted in lower overall death rates and a prolonged survival
(Figures 1A-C). This suggests that it may take longer to establish infection in rats exposed to lower doses, but once established, further dissemination and replication proceeds rather uniformly until death of the animal. It is feasible that serial sacrifice studies conducted at different doses may reveal differences in tissue viral loads at earlier time points after infection. 

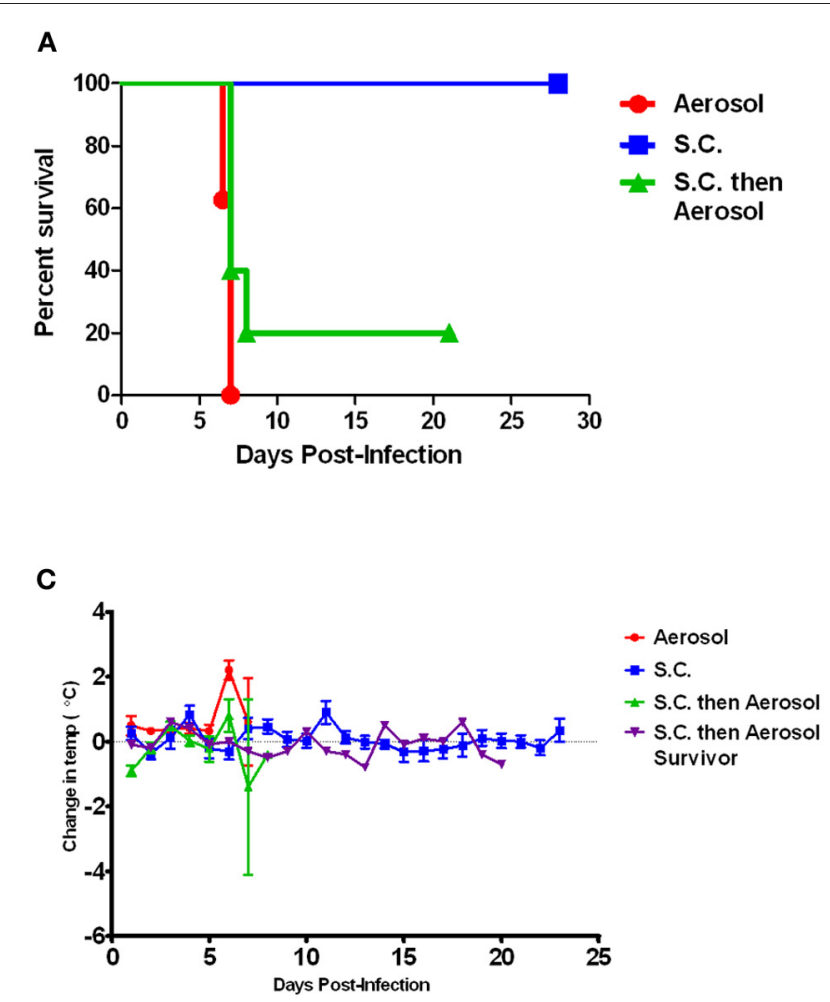

FIGURE 10 | Effect of infection route on survival of Lewis rats.

(A) Shows survival of Lewis rats after either subcutaneous (blue line; $n=5$ ) or aerosol exposure (red line; $n=6$ ). The rats that survived s.c. exposure were re-exposed to RVFV by aerosol infection 28 days after the

In summary, this is the first comparison of RVFV infection in three rat strains after aerosol exposure. In two of the three rat strains, inhalation of RVFV resulted in a disease similar to that seen after s.c. inoculation. Inhalational exposure of WistarFurth and ACI rats to RVFV can serve as a suitable model for the severe hepatic and neurological disease seen in humans, respectively. However, the data from Lewis rats suggests that aerosol exposure may be less likely to result in the milder acute febrile disease seen in humans after mosquito transmission. Therefore, aerosol exposure to RVFV as a result of a biological weapon attack may be more concerning that originally realized, particularly if parenterally administered vaccines are unable to offer good protection from neurological disease. The mechanisms that determine these different outcomes in humans or rats are not

\section{REFERENCES}

Abdel-Wahab, K. S., El Baz, L. M., ElTayeb, E. M., Omar, H., Ossman, M. A., and Yasin, W. (1978). Rift Valley Fever virus infections in Egypt: pathological and virological findings in man. Trans. R. Soc. Trop. Med. Hyg. 72, 392-396.

Anderson, G. W. Jr., Lee, J. O., Anderson, A. O., Powell, N., Mangiafico, J. A., and Meadors, G. (1991a). Efficacy of a Rift Valley

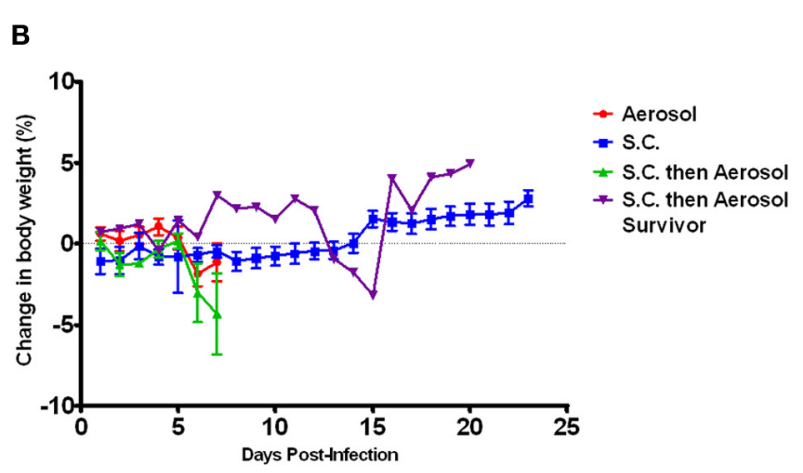

original exposure (green line; $n=5)$. (B,C) Change in body weight and body temperature of Lewis rats after exposure to RVFV as outlined in (A). The purple line shows the single rat that survived aerosol re-challenge. well-understood. Additional characterization of the pathophysiological mechanisms important in disease induction is needed before these models can be considered for potential use under the FDA's Animal Rule (Food and Drug Administration, 2002) for evaluation of the efficacy of potential vaccines and therapeutics.

\section{ACKNOWLEDGMENTS}

The authors would like to thank Stuart Nichol and Brian Bird at CDC/Atlanta and Barry Miller at CDC/Ft. Collins for kindly providing the virus stock used in these studies. This work was supported by the Transformational Medical Technologies program contract HDTRA1-10-C-1066 from the Department of Defense Chemical and Biological Defense program through the Defense Threat Reduction Agency (DTRA). 
virulence in vivo and may provide a model of human delayed onset neurologic disease. Virology 362, 10-15.

Bucci, T. J., Moussa, M. I., and Wood, O. (1981). Experimental Rift Valley Fever encephalitis in ACI rats. Control Epidemiol. Biostat. 3, 60-67.

Coetzer, J. A., and Barnard, B. J. (1977). Hydrops amnii in sheep associated with hydranencephaly and arthrogryposis with wesselsbron disease and rift valley fever viruses as aetiological agents. Onderstepoort J. Vet. Res. 44, 119-126.

Coetzer, J. A., and Theodoridis, A. (1982). Clinical and pathological studies in adult sheep and goats experimentally infected with Wesselsbron disease virus. Onderstepoort J. Vet. Res. 49, 19-22.

Department of Health and Human Services. (2005). 42 CFR Parts 72, 73, and 42 CFR Part 1003. Posession, use, and transfer of select agents and toxins; final rule. Fed. Regist. 70, 13294-13325.

Easterday, B. C. (1965). Rift Valley Fever. Adv. Vet. Sci. 10, 65-126.

Easterday, B. C., McGavran, M. H., Rooney, J. R., and Murphy, L. C. (1962). The pathogenesis of Rift Valley fever in lambs. Am. J. Vet. Res. $23,470-479$.

Food and Drug Administration. (2002). 21 CFR parts 314 and 601. Evidence needed to demonstrate effectiveness of new drugs when human efficacy studies are not ethical or feasible; final rule. Fed. Regist. 67, 37988-37998.

Francis, T., and Magill, T. P. (1935). Rift Valley Fever: a report of three cases of laboratory infection and the experimental transmission of the disease to ferrets. J. Exp. Med. 62, 433-448.

Guyton, A. C. (1947). Measurement of the respiratory volumes of laboratory animals. Am. J. Physiol. 150, 70-77.

Hoogstraal, H., Meegan, J. M., Khalil, G. M., and Adham, F. K. (1979). The Rift Valley fever epizootic in Egypt 1977-1978. 2. Ecological and entomological studies. Trans. R. Soc. Trop. Med. Hyg. 73, 624-629.

Jouan, A., Coulibaly, I., Adam, F., Philippe, B., Riou, O., Leguenno, B., Christie, R., Ould Merzoug, N., Ksiazek, T., and Digoutte, J. P. (1989). Analytical study of a Rift Valley fever epidemic. Res. Virol. 140, 175-186.

Laughlin, L. W., Meegan, J. M., Strausbaugh, L. J., Morens, D. M., and Watten, R. H. (1979). Epidemic Rift Valley fever in Egypt: observations of the spectrum of human illness. Trans. R. Soc. Trop. Med. Hyg. 73, 630-633.

Madani, T. A., Al-Mazrou, Y. Y., AlJeffri, M. H., Mishkhas, A. A., AlRabeah, A. M., Turkistani, A. M., Al-Sayed, M. O., Abodahish, A. A., Khan, A. S., Ksiazek, T. G., and Shobokshi, O. (2003). Rift Valley fever epidemic in Saudi Arabia: epidemiological, clinical, and laboratory characteristics. Clin. Infect. Dis. 37, 1084-1092.

McIntosh, B. M., Russell, D., Dos Santos, I., and Gear, J. H. (1980). Rift Valley fever in humans in South Africa. S. Afr. Med. J. 58, 803-806.

Meegan, J. M., Niklasson, B., and Bengtsson, E. (1979). Spread of Rift Valley fever virus from continental Africa. Lancet 2, 1184-1185.

Miller, W. S., Demciiak, P., Rosenberger, C. R., Dominik, J. W., and Bradshaw, J. L. (1963). Stability and infectivity of Airborne Yellow Fever and Rift Valley Fever viruses. Am. J. Hyg. 77, 114-121.
Mohamed, M., Mosha, F., Mghamba, J., Zaki, S. R., Shieh, W. J., Paweska, J., Omulo, S., Gikundi, S., Mmbuji, P., Bloland, P., Zeidner, N., Kalinga, R., Breiman, R. F., and Njenga, M. K. (2010). Epidemiologic and clinical aspects of a Rift Valley fever outbreak in humans in Tanzania, 2007. Am. J. Trop. Med. Hyg. 83, 22-27.

Morrill, J. C., and Peters, C. J. (2011). Protection of MP-12-vaccinated rhesus macaques against parenteral and aerosol challenge with virulent rift valley fever virus. J. Infect. Dis. 204, 229-236.

Peters, C. J., and Anderson, G. W. (1981). Pathogenesis of Rift Valley Fever. Control Epidemiol. Biostat. 3, 21-41.

Peters, C. J., and Slone, T. W. (1982). Inbred rat strains mimic the disparate human response to Rift Valley fever virus infection. J. Med. Virol. 10, 45-54.

Pratt, W. D., Fine, D. L., Hart, M. K., Martin, S. S., and Reed, D. S. (2012). "Alphaviruses," in Biodefense Research Methodology and Animal Models, ed J. R. Swearengen (New York, NY: CRC Press), 223-254.

Reed, D. S., Lackemeyer, M. G., Garza, N. L., Norris, S., Gamble, S., Sullivan, L. J., Lind, C. M., and Raymond, J. L. (2007). Severe encephalitis in cynomolgus macaques exposed to aerosolized Eastern equine encephalitis virus. J. Infect. Dis. 196, 441-450.

Ritter, M., Bouloy, M., Vialat, P., Janzen, C., Haller, O., and Frese, M. (2000). Resistance to Rift Valley fever virus in Rattus norvegicus: genetic variability within certain 'inbred' strains. J. Gen. Virol. 81, 2683-2688.

Roy, C. J., and Pitt, L. M. (2005). "Infectious disease aerobiology: aerosol challenge methods," in Biodefense: Research Methodology and Animal Models, ed J. R. Swearengen (Boca Raton, FL: CRC Press), 61-76.

Smithburn, K. C., Mahaffy, A. F., Haddow, A. J., Kitchen, S. F., and Smith, J. F. (1949). Rift Valley fever; accidental infections among laboratory workers. J. Immunol. 62, 213-227.

United States Department of Agriculture. (2005). 7 CFR Part 331 and 9 CFR Part 121. Agricultural Bioterrorism Protection Act of 2002; posession, use, and transfer of biological agents and toxins; final rule. Fed. Regist. 70, 13241-13292.

Conflict of Interest Statement: The authors declare that the research was conducted in the absence of any commercial or financial relationships that could be construed as a potential conflict of interest.

Received: 31 May 2012; paper pending published: 05 July 2012; accepted: 15 July 2012; published online: 02 August 2012. Citation: Bales JM, Powell DS, Bethel LM, Reed DS and Hartman AL (2012) Choice of inbred rat strain impacts lethality and disease course after respiratory infection with Rift Valley Fever Virus. Front. Cell. Inf. Microbio. 2:105. doi: 10.3389/fcimb.2012.00105 Copyright (๑) 2012 Bales, Powell, Bethel, Reed and Hartman. This is an openaccess article distributed under the terms of the Creative Commons Attribution License, which permits use, distribution and reproduction in other forums, provided the original authors and source are credited and subject to any copyright notices concerning any third-party graphics etc. 